caused much damage in the East. It rarely attacks very young trees, and develops most rapidly during periods of heavy rain. Manifestations of the disease are extremely variable, but a common form, viz. a pink encrustation on the branches or main stem, gives the disease its popular name. Once the bark is penetrated the fungus spreads rapidly, destroying the cortex, and frequently enters the wood, interrupting the water-supply to the branches, which turn brown and die. So far the best treatment has been the removal of infected branches, or by treating the diseased parts with tar. Except in special cases, spraying is not practicable.

In the section devoted to fungal cultures and preparations, the following fungi, among others, have been isolated and grown from the trunks exhibited: Cyphella heveae, a cause of "thread blight" disease; Botryodiplodia theobromae, a cause of "die-back"; Fomes lignosus; Hyphomycetes associated with Botryodiplodia. In addition to living cultures of these fungi on potato and banana agars, interesting experiments are in progress with the view of ascertaining the effect of the vitality of the host upon the potency of the parasite. The fungi have therefore been sown (on wounds) on apple-twigs respectively healthy, of low vitality, and dead, and the cultures kept in a saturated atmosphere and at $25^{\circ} \mathrm{C}$.

The third section well illustrates by means of diagrams the important relationship between the anatomy of the rubber stem and the yield of latex. In high-yielding trees the bark shows a large number of rings of latex tubes and a high relative proportion of soft bast as compared with hard bast, which latter contains abundant groups of stone-cells interrupting the rings of latex tubes. In good yielders the stonecells are more or less confined to the external part of the cortex; in low yielders they are distributed in depth. The well-known superior yield of tapping cuts made from left to right over cuts made from right to left is due to the oblique course of the latex tubes in the bark. This important fact is explained in a large diagram. Mr. H. Ashplant exhibits elaborate statistics showing individual daily tapping yields obtained by different coolies on one estate over a period of three years. The figures show that highly skilled tappers working a group of trees previously tapped by average or poor tappers may collect from 50 to 200 per cent. more latex than the unskilled men. This fact results from the variable depth of the cut made by the inferior tappers, who do not reach the more internal rings of latex tubes. A further interesting point is the favourable influence of a good tapper's work on the yield obtained by an average tapper succeeding him in the same block.

It is much to be hoped that efforts will be made to maintain and develop the present exhibition as a permanent museum of the economic mycology of Hevea brasiliensis. Such a museum, with its natural complement of an information bureau, would be of the greatest practical value to the home representatives of planting interests and to the industry generally. The exhibition demonstrates in the clearest fashion the supreme importance of scientific research in this vital aspect of rubber-planting. New diseases are bound to occur in the future, and it may be disastrous to wait until the plantations are seriously affected before taking stens to secure expert advice. Adequate scientific staffs should be continuously engaged in studying the complete biology of Hevea, so that in the advent of a new disease experienced specialists could be detailed at once to cope with it. It is, however, essential that such staffs should be composed of men of first-rate ability and training, for where so much is at stake NO. 2629 , VOL. IO5] anything short of the best is worse than useless. Moreover, the best men afford the greatest chance of effecting the desideratum in combating all disease, viz. the stitch in time. The industry must be prepared to pay for such men, but there can be no question that money generously and wisely spent on these lines would be repaid times over.

\section{The Position of the Meteorological Office.}

DR. C. G. KNOT', president of the Scottish Meteorological Society, has sent us a copy of the following resolution passed by the council of the society with reference to the present position of the Meteorological Office :-

"The council of the Scottish Meteorological Society have had under consideration the information published regarding the future status of the Meteorological Office and its relation to various Departments of State They recognise that an incorporation in one of the great Departments of State is desirable and realise that meteorology has much to gain by an intimate connection with the Air Ministry. At the same time they have in view that the State Meteorological Office has many other departments and interests to serve, not the least of which are those of pure research. They feel that any system by which the policy of the Office was directed by the interests of only one Department might in certain circumstances hamper its proper development. The science of meteorology made notable advances in many directions under the liberty enjoyed by the Director of the Office with the administrative committee as constituted in 1905. The council urge that, whatever constitution it may be convenient to give to the Office, the public, departmental, and scientific interests of the science should be safeguarded by expressly and personally charging the Director with the care of meteorology in all its branches. Under such an instruction the Director could be relied upon to organise the service upon a scientific plan and to build up the administrative elements in accordance with the demands made upon him. The council alss feel that any step which will modify the functions and responsibilities of the Meteorological Committee should be taken onlv after searching inquirv by a Departmental Committee into the necessity for anv modification, and the probable effect of such modification on the work of the Meteorological Committee."

\section{Earthworks and Retaining Walls.}

$\mathrm{T}^{\mathrm{T}}$ is admitted that our knowledge of earthwork problems is far from complete, and the information given in two papers read at the Institution of Civil Engineers on February ro forms a welcome addition. Mr. Ponsonby Moore Crosthwaite has made experiments on the horizontal pressure of sand, and finds that the angle of internal friction is much less than the angle of repose. The experiments show that the pressures on a wall, as calculated from the Rankine and Colomb theories, are much too high, especially for surcharged walls. Further experiments show that the wedge theories which take account of the friction between the wall and its backing give correct results if the wall is not surcharged, but break down for surcharged walls. By modifving the wedge thenry so as to neglect the friction on the back of the wall, and introducing the angle of internal frirtion instead of the angle of repose, marked agreement was found with the experiments for surcharged walls. 